\section{Tar Wars Program Remains Unique and Effective}

To the Editor: We appreciate the thoughtful manner in which Johnson and Blum have approached their criticism of our evaluation of the Tar Wars program. In fact, their criticism of the study's methodology was included in the paper's discussion section as recommendations for future evaluations of the program. We continue to maintain that the paper illustrates that Tar Wars meets Center for Disease Control (CDC) guidelines as one component of effective youth tobacco prevention and believe the rejection of the paper's conclusions is overreaching on several accounts.

Tar Wars is unique among youth tobacco prevention programs on several levels; Tar Wars utilizes family physicians as in-school educators, it is offered free to schools, and it is the only tobacco prevention program offered by a national organization of health professionals. Given its ownership by the American Academy of Family Physicians (AAFP), annual participation of more than half a million children, and participation of all 50 local state chapters of the Academy, evaluation of the program is imperative. This evaluation was the first to combine both quantitative and qualitative evaluations of the Tar Wars program.

$\mathrm{K}-12$ school-based youth tobacco prevention is recommended both by the CDC and the US Surgeon General. ${ }^{1,2}$ The CDC DASH 2000 guidelines specifically recommend instruction "about the short-term and long-term negative physiologic and social consequences of tobacco use, social influences on tobacco use, peer norms regarding tobacco use, and refusal skills." 3 The CDC's Logic Model for Reducing and Preventing Youth Tobacco Use recommends that youth receive tobacco prevention in schools with initial outcomes of increased knowledge, awareness, and skills. ${ }^{4}$

All 3 components of the Tar Wars program (preactivity, lesson plan, and poster contest) were included in the evaluation. The Tar Wars program does not focus on the dangers of tobacco use. Rather the lesson is concerned with the short-term, image-based consequences of tobacco use, peer norms, and tobacco advertising. Quantitative evaluation showed significant changes in all 14 questions evaluated, including 7 of the 9 knowledge portions of the 1994 CDC Guidelines for School Health Programs to Prevent Tobacco Use and Addiction. ${ }^{3}$ Larger changes were shown in 3 sections specifically recommended by the CDC, with increases shown in student understanding about peer norms, cost of tobacco use, and truth of tobacco advertising.

We acknowledged in the paper that state funding and the resulting strict limitations on time produced a shortterm evaluation. Following a cohort of subjects over a longer time would make an interesting future study.

Moreover, Johnson and Blum have failed to acknowledge the qualitative portions of the evaluation which reinforce the quantitative evaluation. Students, school teachers, and presenters all agreed that new information was being presented on the cost of smoking, the real percentages of youth and adults who use tobacco, and how tobacco is advertised. As reported in the paper, most students already know that tobacco use is harmful and causes long-term health effects; however, all thought that the details about the short-term effects, peer norms, advertising, and other information was new and helped them understand why they should not use tobacco. Many repeatedly emphasized the importance of hearing these lessons.

We would like to thank Johnson and Blum for the challenges they presented and would recommend that their concerns be included in the next round of studies of the Tar Wars program. We believe the paper does demonstrate that Tar Wars meets CDC guidelines as one component of effective comprehensive youth tobacco prevention and would welcome additional feedback. This paper was recognized as the best research presentation overall at the 2006 AAFP Scientific Assembly.

Jeffrey J. Cain, MD

Department of Family Medicine, The Children's Hospital, Denver, CO; Department of Family Medicine, University of Colorado Health Sciences

Center, Aurora, CO cain.jeffrey@tchden.org W. Perry Dickinson, MD Douglas Fernald, MA Caroline Emsermann, MS L. Miriam Dickinson, $\mathrm{PhD}$ David West, $\mathrm{PhD}$ Department of Family Medicine, University of Colorado Health Sciences Center, Aurora, CO

\section{References}

1. US Department of Health and Human Services. Reducing tobacco use: a report of the Surgeon General. Atlanta, GA: US Department of Health and Human Services, Centers for Disease Control and Prevention, National Center for Chronic Disease Prevention and Health Promotion, Office on Smoking and Health, 2000.

2. Centers for Disease Control and Prevention. Best practices for comprehensive tobacco control programs-August 1999. Atlanta, GA: US Department of Health and Human Services, Centers for Disease Control and Prevention, National Center for Chronic Disease Prevention and Health Promotion, Office on Smoking and Health, 1999.

3. Centers for Disease Control and Prevention/Divisionof Adolescent and School Health. Guidelines for school health programs to prevent tobacco use-2000. Atlanta, GA: US Department of Health and Human Services, Centers for Disease Control and Prevention, National Center for Chronic Disease Prevention and Health Promotion, Office on Smoking and Health, 2000.

4. Center for Disease Control and Prevention. Preventing the initiation of tobacco use among young people, Appendix B. 2000:111-13.

5. Guidelines for school health programs to prevent tobacco use and addiction. Centers for Disease Control and Prevention. MMWR Morb Mortal Wkly Rep 1994;43(RR-2):1-18

doi: 10.3122/jabfm.2008.01.070224 